Article

\title{
A Spatially Explicit, Multi-Criteria Decision Support Model for Loggerhead Sea Turtle Nesting Habitat Suitability: A Remote Sensing-Based Approach
}

\author{
Lauren Dunkin ${ }^{1}{ }^{*}$, Molly Reif ${ }^{2}$, Safra Altman ${ }^{1}$ and Todd Swannack ${ }^{1}$ \\ 1 U.S. Army Engineer Research and Development Center, 3903 Halls Ferry Road, Vicksburg, MS 39180, USA; \\ safra.altman@usace.army.mil (S.A.); todd.m.swannack@usace.army.mil (T.S.) \\ 2 U.S. Army Research and Development Center, Joint Airborne Lidar Bathymetry Technical Center \\ of Expertise, 7225 Stennis Airport Road, Suite 100, Kiln, MS 39556, USA; molly.k.reif@usace.army.mil \\ * Correspondence: lauren.m.dunkin@usace.army.mil; Tel.: +1-228-596-4780
}

Academic Editors: Deepak R. Mishra, Richard W. Gould Jr. and Prasad S. Thenkabail Received: 12 April 2016; Accepted: 30 June 2016; Published: 6 July 2016

\begin{abstract}
Nesting habitat for the federally endangered loggerhead sea turtle (Caretta caretta) were designated as critical in 2014 for beaches along the Atlantic Coast and Gulf of Mexico. Nesting suitability is routinely determined based on site specific information. Given the expansive geographic location of the designated critical C. caretta nesting habitat and the highly dynamic coastal environment, understanding nesting suitability on a regional scale is essential for monitoring the changing status of the coast as a result of hydrodynamic forces and maintenance efforts. The increasing spatial resolution and temporal frequency of remote sensing data offers the opportunity to study this dynamic environment on a regional scale. Remote sensing data were used as input into the spatially-explicit, multi-criteria decision support model to determine nesting habitat suitability. Results from the study indicate that the morphological parameters used as input into the model are well suited to provide a regional level approach with the results from the optimized model having sensitivity and detection prevalence values greater than $80 \%$ and the detection rate being greater than $70 \%$. The approach can be implemented in various geographic locations to better communicate priorities and evaluate management strategies as a result of changes to the dynamic coastal environment.
\end{abstract}

Keywords: LIDAR; sea turtle; morphology; nesting habitat; remote sensing

\section{Introduction}

In 2014, beaches along the Atlantic Coast and Gulf of Mexico were designated as critical habitat by the U.S. Fish and Wildlife Services (USFWS) for nesting sites of the federally endangered loggerhead sea turtle (Caretta caretta) [1]. The coastal areas that were designated as critical habitat for the C. caretta include approximately 700 miles of terrestrial shoreline that are deemed suitable for nesting habitat based on sand characteristics, lighting considerations, and beach properties of natural and maintained areas [1]. Previous research has focused on quantifying geophysical characteristics that are preferred for nesting habitat of the $C$. caretta. The physical and chemical characteristics include sand properties, moisture, salinity, and temperature [2]. Nesting suitability is routinely determined based on nesting density and other site specific information about the beach characteristics that are identified via in-situ techniques. These techniques require extensive field campaigns on a local scale and may involve ad-hoc methods of recording nesting sites. Morphological characteristics have also been studied to determine preferred ranges for $C$. caretta nesting habitat. High nesting density was found to be associated with beaches that have steep slopes, narrow beach widths, shallow nearshore, defined berm 
features [2-7] and dunes, which provide a change in gradient from the beach that may be an indicator of protection and reduce light pollution [8]. The preferred ranges for the morphological characteristics have been found to be site dependent since the hydrodynamic forces that influence beach properties vary along the coast [2].

Environmental and anthropogenic parameters have also been found to influence the quality of nesting habitat. Studies have shown that nests tend to be clumped near the border between open sand and supra-littoral or littoral vegetation $[9,10]$. Vegetation presence and characteristics, such as type and density, may also impact sand temperatures and therefore decrease the overall incubation temperature [11,12] as well as risk to predation. In addition, vegetation reduces beach erosion, increasing stability and attractiveness to nesting suitability $[8,12]$. Light pollution from beachfront development has been found to disorient and disrupt both nesting females as well as hatchlings, increasing mortality rates $[5,8,12-14]$.

The coastal environment is highly dynamic with waves and currents acting as the primary drivers for changes in the morphology. The temporal scale of morphological change can vary from hours to seasons. In addition to these natural drivers, the coastal environment is also subject to man-made changes that include replenishment of sand to the littoral system or other structural alternatives. Given the expansive geographic location of the designated critical C. caretta nesting habitat and the highly dynamic coastal environment, understanding nesting suitability on a regional scale is essential for monitoring the changing status of the coast as a result of hydrodynamic forces and maintenance efforts. The increasing spatial resolution and temporal frequency of remote sensing data offer the opportunity to study this dynamic environment on a regional scale. Lidar data have been used to identify morphological preferences [7] and how nesting is impacted by the changing environment [3,15]. Yamamoto et al. [4] used lidar-derived elevation products to identify preferred ranges for morphological features along nesting beaches. In combination with lidar data, the use of imagery is ideal for extracting environmental parameters, such as dune vegetation.

While the specific beach characteristics that are preferred by the $C$. caretta for nesting habitat are well documented, limited literature exists that describes the use of models to determine nesting habitat preference for any sea turtle species. Spatially-explicit ecological models that utilize a Geographic Information System (GIS) framework are fairly standard practice for identifying marine resources and migration patterns of sea turtles [16-18], but the terrestrial component of the nesting habitat has not been widely explored. Using environmental variables measured with field techniques as input, Santos et al. [13] developed three Habitat Suitability Index models that were weighted according to: (1) expert opinion; (2) regression analysis; and (3) a combination of suitability indices with regression. The three models had a $40 \%$ prediction rate, which the authors hypothesize would be improved with more extensive field data and a larger study area [13]. Relying solely on field measurements as input into nesting suitability models that seek to make assessments on a regional scale is not ideal due to the arduous task of acquiring the level of detail needed to understand nesting habitat suitability.

Habitat suitability index models were developed initially to assess habitat quality for a species based on field measurements or expert opinion of the relationship between habitat attributes and species' life history $[19,20]$. The increase in availability of high resolution remotely-sensed data resulted in revisiting some of the older models to determine if accuracy can be improved [21]. High resolution lidar improved accuracy of models developed for amphibians [22], trees [23], and birds [24], but has not been applied to sea turtle nesting sites. Further, the use of high-resolution data can reduce uncertainty associated with trial-and error approaches and can provide standardized, broadly applicable methods [25-27].

This study aims to address the need for a regional approach that leverages available remote sensing data to determine relative nesting habitat suitability by: (1) implementing a multi-criteria weighted modeling approach that uses lidar-derived parameters as input; and (2) developing standardized methods that can be implemented in various geographic locations to better communicate priorities and evaluate management strategies as a result of changes to the dynamic coastal 
environment. Ultimately, the results from this approach can be used by planners and managers to: (1) coordinate with conservation organizations; (2) identify areas to potentially improve nesting habitat through various efforts that could include beneficially managing sediment for project improvement; (3) monitor changes to the suitability of nesting habitat as a result of project implementation; and (4) predict future scenarios of nesting suitability during the project design phase.

\section{Methods}

\subsection{Study Area and Data Collection}

The USFWS designated areas along the U.S. Atlantic and Gulf of Mexico coast as critical habitat by dividing the coast into five distinct recovery units [28]. The study area includes a $200 \mathrm{~km}$ stretch of the southeastern portion of Florida, USA (Figure 1) that lies within the Southeastern Florida region of the Peninsular Florida Recovery Unit $[28,29]$. The Southeastern Florida region was further divided by USFWS into 20-km sections to better align with the average nest site fidelity, which ranges from 3.0 to $17.48 \mathrm{~km}$ for the Florida Atlantic coast [30] to $28.1 \mathrm{~km}$ for the Southwest Florida coast [31]. Nesting data from 2006 to 2011 were used to determine nesting density for the 20-km sections for the Southeastern Florida region where the nesting densities were divided into four equal groups (high, medium, low, no data) using the data for the region to ensure a good spatial representation within the Peninsular Florida Recovery Unit [28]. Sea turtle nesting density data for our study area within the Southeastern Florida region indicate medium to high nesting density for the C. caretta [1]. In addition, this area of Florida also has numerous U.S. Army Corps of Engineers (USACE) navigation and coastal storm damage risk reduction projects making it an ideal location to determine relative suitability of nesting habitat as it relates to these projects for planning and operations.

Remote sensing data were obtained from the Joint Airborne Lidar Bathymetry Technical Center of Expertise as part of the USACE National Coastal Mapping Program (NCMP). The NCMP surveys the sandy shorelines of the U.S. on a recurring basis to provide high airborne data to support operational and planning activities on a regional scale. The southeastern portion of Florida was surveyed from 31 August to 3 October 2009. This survey time period overlaps with the latter half of the C. caretta nesting season which occurs from May through the end of October [1]. Having survey data that overlap with the nesting season is important for ensuring the physical conditions of the beach are consistent with the conditions the nesting turtle would encounter. Following the active 2004-2005 tropical cyclone season for the East coast of Florida, the 2006-2009 timeframe was a period of tropical quiescence. The NCMP provides high resolution topographic and bathymetric lidar data in addition to concurrent hyperspectral imagery. The remote sensing data were collected using the Compact Hydrographic Airborne Rapid Total Survey (CHARTS) system that includes Optech's Scanning Hydrographic Operational Airborne Lidar Survey (SHOALS)-3000T20, with a 3-kHz bathymetric lidar and a 20-kHz topographic lidar, an Itres CASI-1500 for hyperspectral imaging, and a DuncanTech-4000 digital camera [32]. The lidar data were collected at 1-m spot spacing with \pm 15 -cm elevation accuracy, and digital elevation models (DEMs) were developed at 1-m spatial resolution using a variety of software including Applied Imagery's Quick Terrain Modeler 6.0.6 and Environmental Systems Research Institute (Esri) ArcGIS 10.1. DEMs were resampled to 5-m spatial resolution to allow for efficient processing of the extensive study area while also maintaining a high resolution to extract the spatial parameters. In addition to efficient processing time, the 5-m grid is of sufficient spatial resolution since the biological response of the nesting sea turtle has been documented to have nest site fidelity of approximately 20-km [31]. The hyperspectral imagery was likewise resampled to 5-m and included 36 spectral bands between 380 and 1050 nanometers. In addition, imagery was radiometrically and atmospherically corrected using procedures within Harris Geospatial Solutions ENVI 4.5 software environment. Remotely sensed, high resolution data are uniquely available to assist with this effort to demonstrate the value of using remote sensing techniques to determine relative nesting habitat suitability. As future surveys become available, the impacts of operations and planning efforts can be 
observed and used to assess changes in the nesting habitat and identify areas that would benefit from additional support.

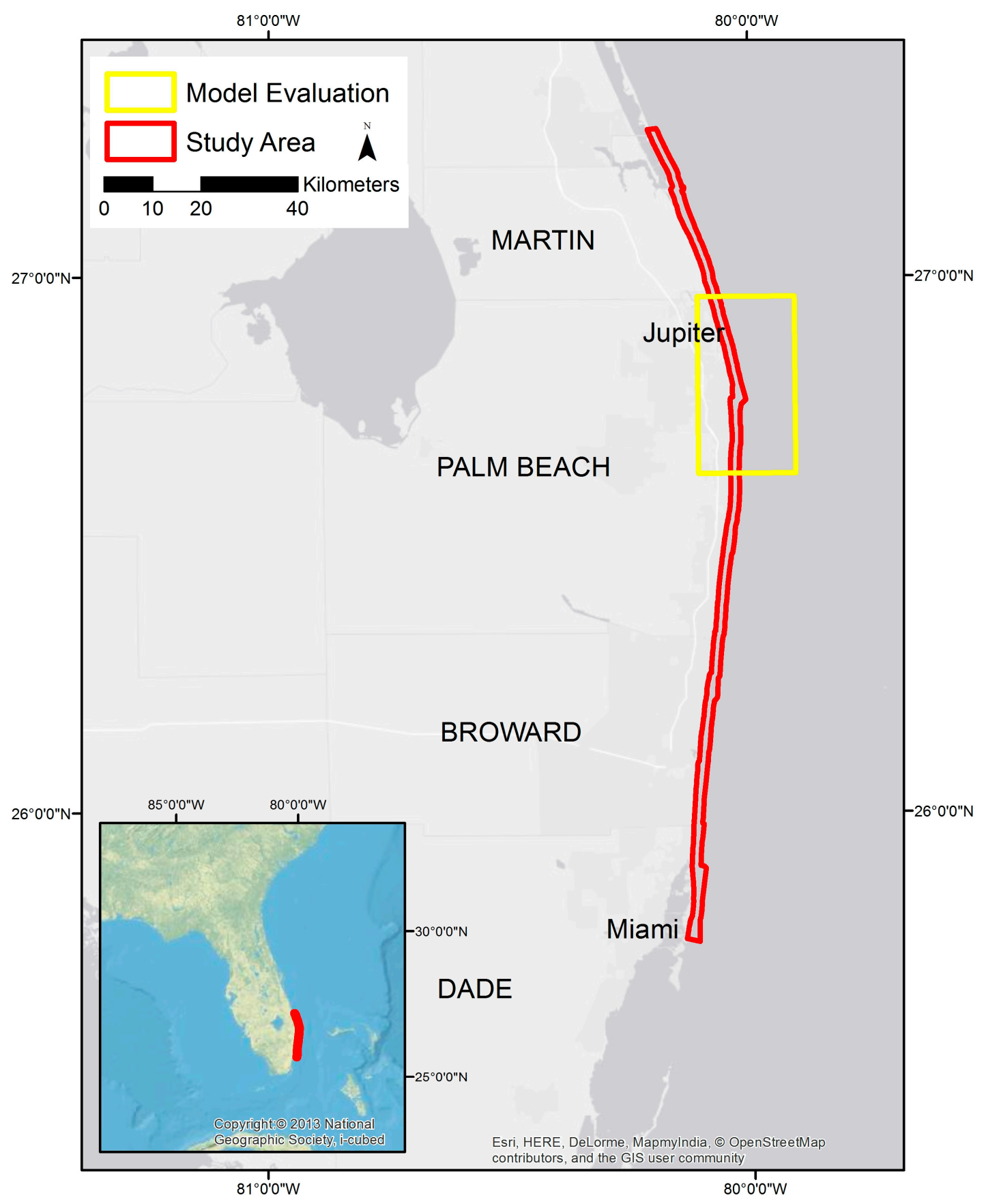

Figure 1. Study area along the South East of Florida.

\subsection{Spatial Parameters}

The lidar-derived elevation grid and the hyperspectral imagery were used to extract parameters that were selected as being important for the nesting of $C$. caretta based on extensive literature review and input from subject matter experts. A conceptual model was developed that listed all of the morphological, environmental, anthropogenic, and habitat parameters that were found to relate to nesting of the C. caretta. The model was further refined based on knowledge about realistic spatial and temporal resolutions of the parameters [33]. Table 1 lists the spatial parameters that were included 
in the final conceptual model and indicates the morphological parameters that were reviewed using multinomial logistic regression analysis to determine the relationships between the parameters and nesting density for the development of the model curves.

Table 1. List of spatial parameters and datasets and the data source.

\begin{tabular}{ccc}
\hline & Parameters & Data Source \\
\hline \multirow{2}{*}{ Morphological } & Beach Slope & 2009 Lidar \\
& Beach Elevation (bare earth) & 2009 Lidar \\
& Beach Width & 2009 Lidar \\
& Dune Elevation & 2009 Lidar \\
\hline Environmental * & Dune Vegetation & 2009 Hyperspectral \\
\hline Anthropogenic * & Potential for Artificial Lighting & 2009 Lidar and 2011 NLCD \\
\hline${ }^{*}$ Denotes parameters not included in the regression analysis or model.
\end{tabular}

Four morphological parameters were developed for statistical evaluation: slope, elevation, beach width, and dune peak. A raster grid with a cell size of $5 \mathrm{~m}$ was generated for each parameter. The beach elevation grids, first return and bare earth, were generated from the 2009 lidar dataset that resulted from including all elevation points and then removing buildings and vegetation, respectively. Dune peaks were extracted from the bare earth elevation grid using a semi-automated routine to extract profiles at a 5-m spacing in the longshore direction to determine changes in slope that have peaks landward of the berm with the first dune being selected as the primary dune [34]. The bare earth elevation grid was used to ensure seasonal changes to vegetation were not extracted as the dune feature. A 5-m buffer was generated on the seaward side of the dune to characterize the dune field and provide a continuous line representing the dune toe. In areas that did not have a primary dune before buildings or roads, the back of the berm was used as the "no dune" point. Adjoining dune points were merged to generate a line. Similarly, the no dune points were used to create a line. These two lines were then merged to create a single line with the two attributes for the entire length of the study area. The dune toe line was used as the landward boundary since it was hypothesized that the C. caretta would not traverse behind the dune area for nesting since on steeply sloped beaches, nests tend to cluster at the base of the dune [2]. The 25-cm contour was extracted from the bare earth elevation grid and used as the seaward boundary to ensure that a continuous line would be extracted from the grid regardless of data gaps that may be present in the swash zone. In addition, the 25-cm contour is used as a shoreline proxy that aligns with the mean high water elevation for this region, which ranges from 28-cm to 7-cm with respect to NAVD88 [35]. The dune line and shoreline formed the boundary for the nesting area of interest. The beach elevation grids were clipped to this boundary. A beach slope raster grid was generated using the spatial analyst tool from the bare earth elevation grid and was clipped to the nesting area of interest. Beach width was determined using the Euclidean distance function within ArcGIS to generate a distance grid from the shoreline to the dune line [36]. In order to develop a grid of beach width values, the maximum distance value was extracted for 5-m bins, in which individual bins were delineated based on the cell size and extent and oriented perpendicular to the shoreline. Thus, the grid depicted each 5-m shore-perpendicular bin with a single beach width (maximum distance) value clipped to the nesting area of interest.

Additional parameters, dune vegetation and potential for artificial lighting, were also developed; however, they were not evaluated in the regression analysis or included in the model since they are considered secondary to site selection and may be more useful for exploring habitat characteristics or condition. In addition, these parameters are not readily available in a high resolution format and in the case of this study, a generalized approach was taken to develop approximations for artificial light potential and dune vegetation. Given that purpose of this study is to explore the use of remotely sensed data, these parameters, though inherently limited, may help offer a simple yet, qualitative first-step in which to glean potential opportunities for further examining habitat 
characteristics. As such, available hyperspectral imagery was used to approximate dune vegetation and subsequently, non-vegetated pixels within the beach area only. The Normalized Difference Vegetation Index (NDVI) ratio is a common band math function to distinguish pixels with vegetation (reflecting in the near-infrared) from those that do not contain vegetation and, thus, do not reflect in the near-infrared part of the electromagnetic spectrum [37]. In this case, it was calculated by dividing the difference in the near-infrared (CASI band 28) and red (CASI band 15) bands by the sum of the same near-infrared and red bands for each pixel. The analysis was limited to areas between the dune line and the $25-\mathrm{cm}$ contour line and thus, the primary materials were sand and vegetation, which have different spectral properties. Since field validation was not possible for this study, high resolution aerial photography from Google Earth Pro's Time Slider Tool was used to help positively identify pixels with dune vegetation in the 2009 timeframe and select an NDVI threshold value. Visual comparisons were made between the Google Earth imagery and the NDVI grid, resulting in the selection of an NDVI threshold value of 0.3 to approximate dune vegetation presence. Thus, pixels with an NDVI value $>0.3$ were defined as dune vegetation present, while pixels with an NDVI value $<0.3$ were defined as dune vegetation absent. This approach represents a restricted approximation of vegetation presence and does not relay details about vegetation type, health, or quality. Additional field data could be used to improve the accuracy and level of vegetation detail that could be extracted from the hyperspectral imagery.

Similar to the dune vegetation, potential for artificial lighting, was likewise approximated for exploring habitat characteristics. Data illustrating nighttime observation of lights are provided through the National Oceanic \& Atmospheric Administration's National Centers for Environmental Information. The Earth Observation Group includes the Defense Meteorological Satellite Program with visible and infrared sensors (DMSP-OLS) Nighttime Lights Series, collected by the U.S. Air Force Weather Agency. In this study, the data were not directly used because of the coarse spatial resolution relative to the morphological parameters $\left(1 \mathrm{~km}^{2}\right.$ at the equator); however, the 2011 average visible lights data were downloaded and used indirectly for comparison with the 2011 National Land Cover Database (NLCD) [38] in order to examine the relationship between visible nighttime lights and land use. A one-way ANOVA revealed significantly different means for visible light with high NLCD values than low NLCD values (low NLCD mean visible light $=34.47$, high NLCD mean visible light $=63$, $\mathrm{F}=1479, p<0.001)$. Since it was out of the scope of this study to use site-specific, ground data (e.g., such as from lighting ordinances during nesting season), the approximation for light pollution potential is based on medium and high intensity urban land use that may be visible in areas between the dune line and the $25-\mathrm{cm}$ shoreline contour. This approximation assumes that high intensity urban areas are more likely to produce light pollution in the area of interest. It should be noted, however, that a handful of houses with bright lights can be more damaging than those in urban areas with light dampening measures in place. Thus, this approximation only captures generalized lighting trends associated with heavily urbanized areas and may miss localized instances of light pollution. Using the dune line as the backline, the $25-\mathrm{cm}$ shoreline contour, and the first return elevation grid as input, the Viewshed tool was used to determine line of sight for an approaching sea turtle from the shore. Land cover data from the 2011 NLCD [38] was used to discriminate urban versus natural areas, in which pixels designated with medium and high intensity urban values within $200 \mathrm{~m}$ of the dune line were flagged as having the potential for far-reaching light pollution in the beach area of interest. Combining the visible pixels from the Viewshed analysis with the nearby flagged light pollution pixels from the land cover grid resulted in a proxy for artificial light pollution. Although light could extend beyond urban pixels, it was assumed that only those pixels found to be visible in the beach area of interest to those with medium and high intensity urban values would represent a starting point for assessing areas with broad potential impacts. It may be possible for artificial light pollution to spill into pixels identified as not visible in the Viewshed analysis and, ultimately, localized assessment of lighting ordinances would yield specific light pollution effects. 


\section{Regression Analysis}

The study area comprised all medium and high nesting density designations as defined by the Florida Fish and Wildlife Conservation for the C. caretta. In addition, the nesting density designations are highly generalized with data reported at the county beach level, which are typically 20-km along the coast for a single section of the nesting density line. We subdivided the 39 beach area densities into relative densities for this stretch of coastline since this area is designated as having either medium to high nesting densities. The mean value nesting density for the study area is 198, with a standard deviation of 200. The three class designations were preserved and were divided as follows: less than 100 (low), between 101 and 300 (medium), and greater than 300 (high). The more detailed subdivision of densities was conducted in order to better quantify and evaluate the relationship between individual morphological parameters and nesting densities. To identify the relationship between each morphological parameter and the predicted probability of nesting density (high, medium, and low), we developed a suite of individual multinomial logistic regressions for each morphological parameter (slope, elevation, beach width, and dune peak). The two elevation grids (first return and bare earth) were found to be highly correlated with a Pearson's correlation coefficient of 0.93 . The bare earth elevation grid was used in the model since it removes any temporal variations that might be present due to seasonal vegetation, debris, or human use of the beach area. None of the other morphological parameters were correlated, and all of the remaining correlation coefficients were below 0.4. As stated, the dune vegetation and artificial lighting parameters were not evaluated in the regression analyses. Rather, they were set aside for comparison with the model results to illustrate potential habitat quality. To that end, these parameters were used as general proxies for habitat quality and may provide an initial way to target more detailed opportunities for managers to find and improve habitat quality.

The predicted probability graphs based on beach slope and beach width are shown in Figure 2. Wald tests, used to evaluate the statistical significance of coefficients in each model, showed that each morphological parameter was a significant variable in its respective model (beach slope Wald's $p=0.001$, beach width Wald's $p=0.01$ ). It is inappropriate to use traditional $\mathbf{R}^{2}$ values to interpret model performance of logistic regressions. Pseudo $\mathrm{R}^{2}$, though difficult to interpret, indicates that it is reasonable to use the individual morphological parameter models to inform suitability curves (beach slope McFadden's $R^{2}=0.63$, beach width Mcfadden's $R^{2}=0.21$ ). The predicted probability graph based on beach slope shows the trends for the three relative density classes (low, medium, and high) and compares with expected results since the $C$. caretta prefers steeply sloped beaches for nesting [2-7]. The low nesting probability is highest for the mild slopes ranging from 0 to 4 degrees. The medium nesting probability has a bell shaped curve with the peak probability occurring around 9 degrees. The high nesting probability grows quickly with the 0.5 probability occurring around 10 degrees. The end tail for the high nesting probability continues to increase with the increasing slope that occurs near the dune field. For the model development, the threshold was capped at 15 degrees since values beyond this range occur at the back of the grid where the dunes are located. The beach width predicted probability curves show that as the beach width increases, the nesting probability class changes from medium to low. Beach widths greater than 100-m should indicate low nesting density habitat. While the overall trend is in-line with expected results, the high and medium nesting density classes both have a lower probability value for the narrow beach widths than was expected. As stated previously, this may be a result of the generalized nesting density line that reports data for county beaches along the coast where beach width may vary considerably alongshore within the county beach. 
A

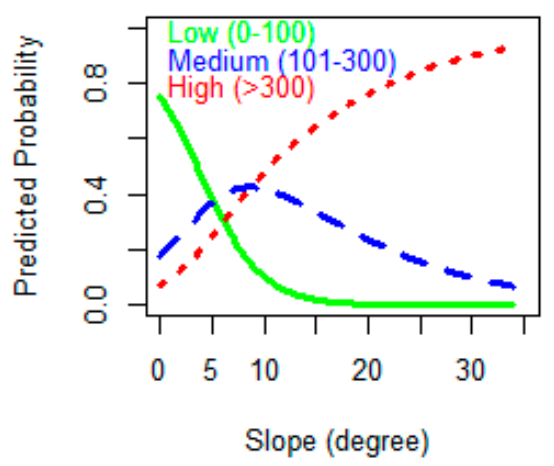

C

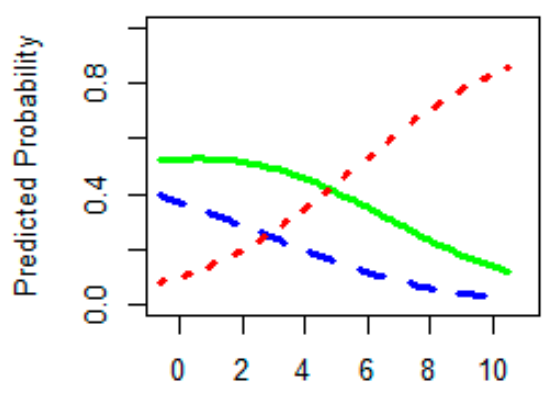

Bare Earth Elevation $(\mathrm{m})$
B

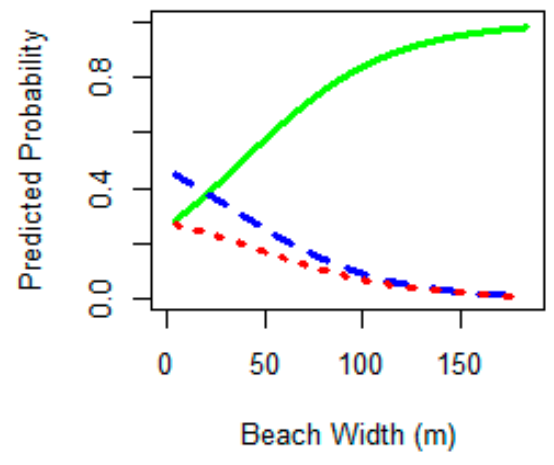

D

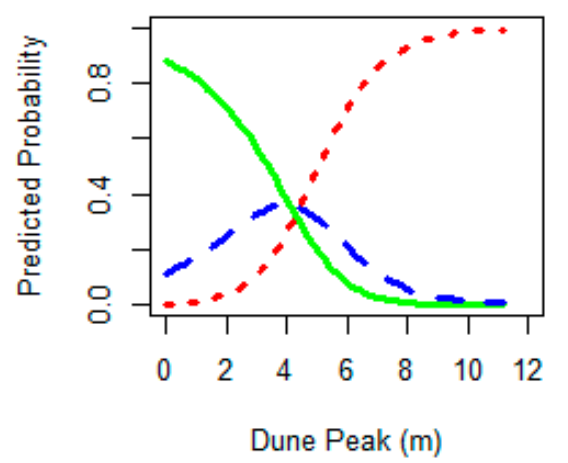

Figure 2. Predicted probability of $C$. caretta nest density based on: (A) beach slope; (B) beach width parameter; (C) bare earth elevation; and (D) dune peak parameter. Predicted probabilities determined through multinomial logistic regression run on individual parameters.

The predicted probability graphs based on bare earth elevation and dune elevation are also shown in Figure 2. As in the previous models, the bare earth elevation and dune elevation coefficients were statistically different from zero and pseudo $\mathrm{R}^{2}$ values were above 0.2 (bare earth elevation Wald's $p<0.001$, McFadden's $\mathbf{R}^{2}=0.79$; dune peak Wald's $p<0.05$, McFadden's $\mathbf{R}^{2}=0.38$ ). Higher nesting density is expected in areas with higher elevations. Since elevation and slope are related, the trend for the high nesting density follows that of slope. The predicted probability for the medium class is more surprising in that the greatest values are seen at the lowest elevations. This is likely a result of the highly generalized nesting density data, which are considered medium/high for this area. The lowest nesting class shows a similar trend with the slope, with the greatest probability of having a low nesting density occurring at the lower elevations. Lower elevation areas are typically not considered to be ideal nesting habitat because of the risk of inundation or overwash [2]. The lower nesting class curves align with elevations in the 3-m range with a steady decline to show that at the next step with elevations greater than 3-m the nesting classes transitions to a medium/high class. The lower dune peaks have a high probability of being in the low nesting class. These results are expected given the role dunes provide to block light and their indication of the stability of the coastal area. The medium class shows a similar trend with the slope that the peak probability is around the 4-m elevation. The high class shows the greatest probability of occurring with the dune peaks are at an elevation greater than 4-m. The dune peaks over 7-m are greater than one standard deviation from the average dune elevation and occur in limited locations within the study area. These high dune elevations only account for two percent of the total dune peak elevations for the entire study area and are primarily observed in portions of Palm Beach County where there are densely vegetated dune fields. 


\subsection{Model Development}

The four morphological spatial parameters form the foundation of the model. Each parameter is represented quantitatively as suitability indices ranging from 0 to 1 (unsuitable to highly suitable, respectively) Figure 3. The regional variability necessitates deriving the suitability curves for the study area by utilizing the regression curves to determine transition points in addition to relying on value ranges documented in the literature and vetted by subject matter experts. The graphs of the curves are provided in Figure 3 and the supporting equations for the parameters for this study area are provided in Appendix A.

More specifically, the $C$. caretta have been documented in the literature to nest more frequently on steeper sloped beaches that have a range of $9 \pm 2$ degrees for southeast Florida [2,5] and similarly also corresponds to what the regression curves in Figure 2A show with the transition point from medium to high occurring at 9 degrees. The slope curve in Figure 3A linearly increases in suitability from 0 to 8 degrees and then peaks for values from 8 to 11 degrees before decreasing for the slopes greater than 11 degrees.

Similarly, C. caretta have been documented to prefer narrow beaches that have values around $33 \pm 5.6 \mathrm{~m}$ [2], which is evident in the regression curves in Figure $2 \mathrm{~B}$ that transition from low predicted probability to high/medium predicted probability at the 30-m width. The suitability index curve in Figure 3B highlights this preference of the C. caretta for narrow beaches with the right-skewed distribution curve that peaks at 30-m.
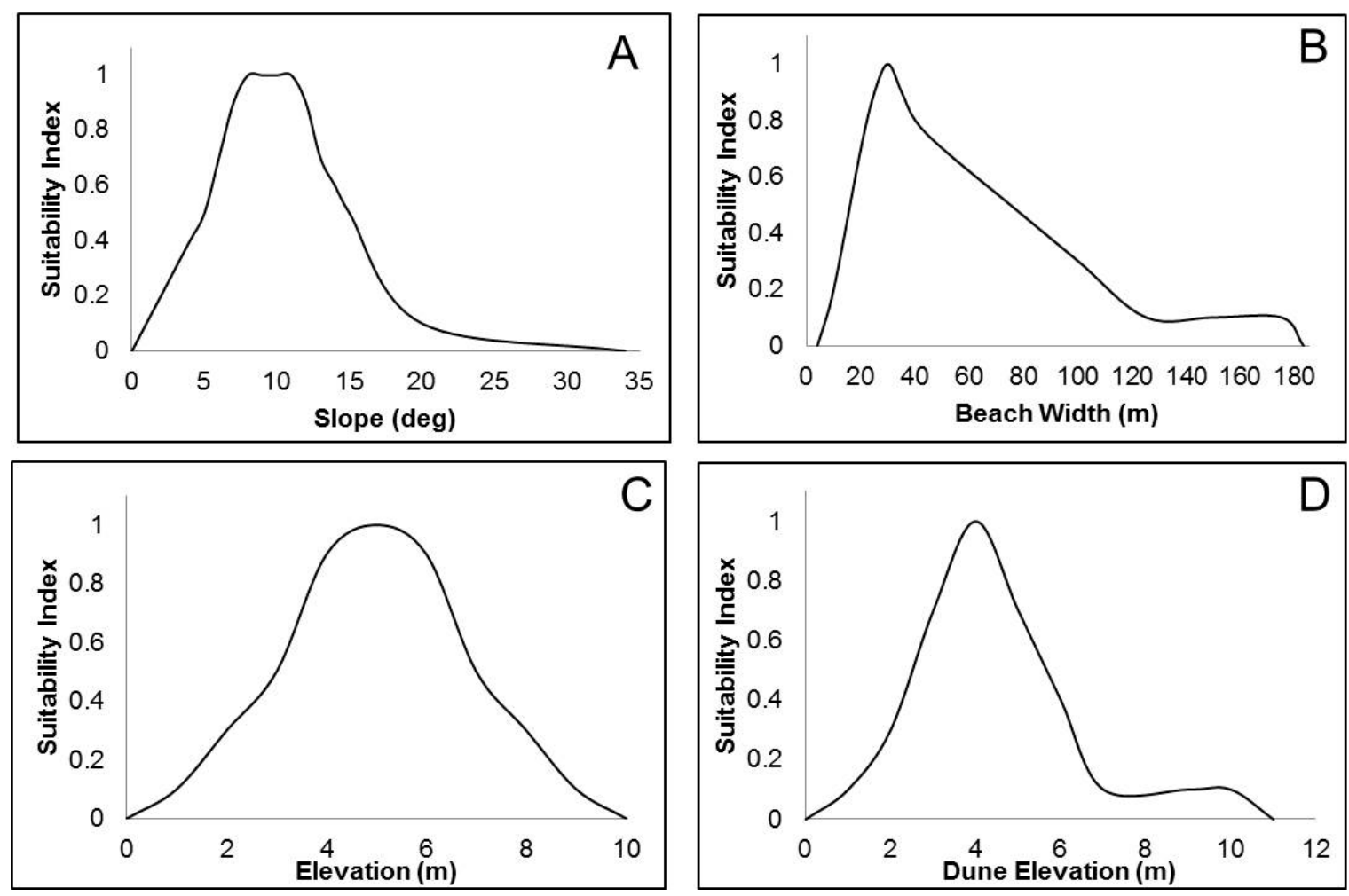

Figure 3. Suitability index curves for: (A) beach slope; (B) beach width; (C) elevation; and (D) dune elevation.

Beach elevation has been found to influence nesting location since the elevation provides protection of the nest from inundation or overwash [2]. This is also seen in the regression curves (Figure 2C) where the transition point from low to high predicted probability occurs at 4-m. The suitability index curve is normally distributed around the 4-m elevation to account for the lower suitability of the lowest and highest elevation value ranges. 
Similar to the beach elevation suitability curve generation process, the dune elevation regression curves were used to determine the elevation where the predicted probability transitions from low to high. This occurs at the 5-m elevation for dune peak and results in a suitability curve that increases and decreases rapidly since a majority of the dunes have elevation between 3.5-m and 6-m.

The model curves were used to generate raster grids to scale each of the four morphological parameters from 0 to 1 based on the spatial data. An example of the rasterized model grids is shown in Figure 4.
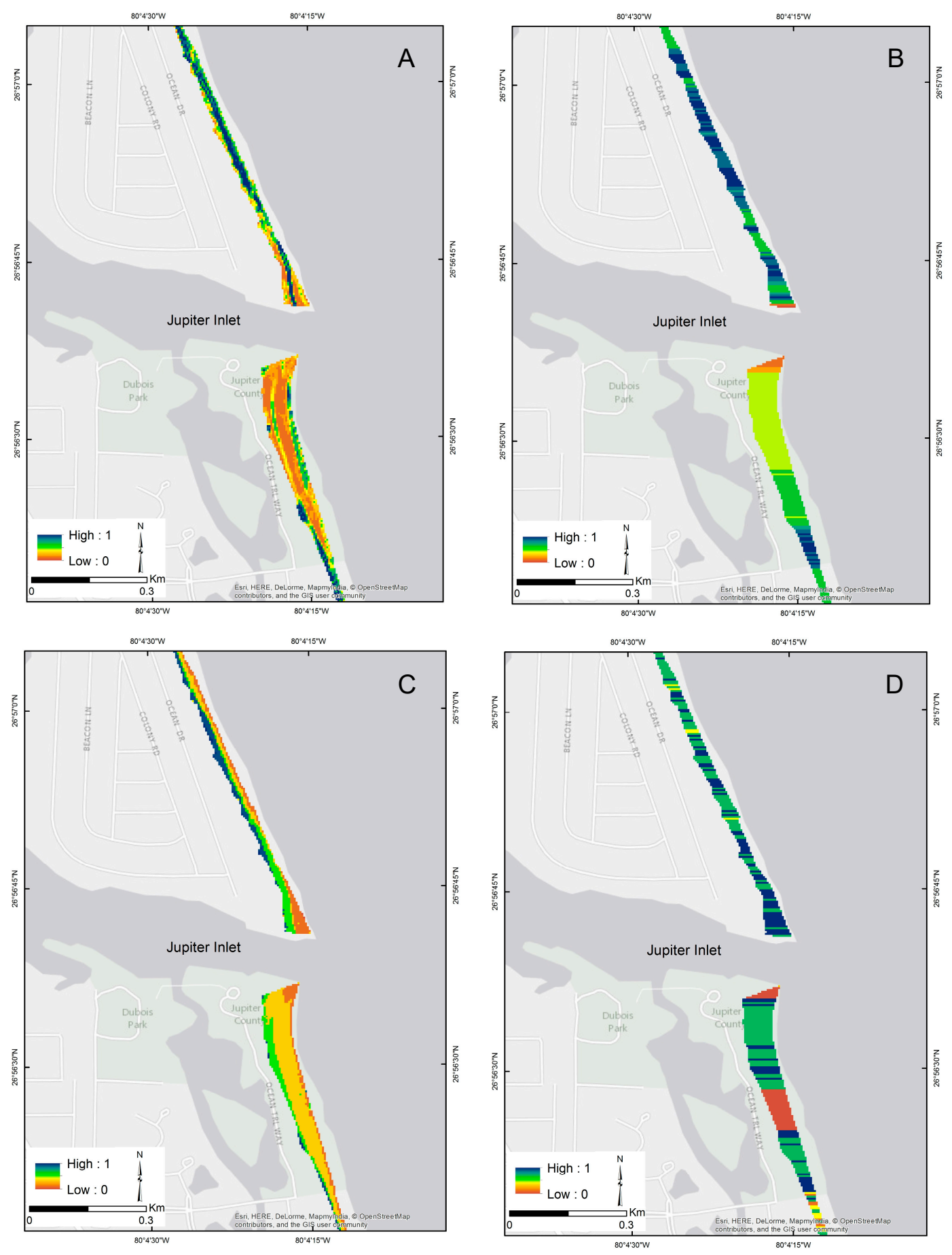

Figure 4. Rasterized model grids for: (A) slope; (B) beach width; (C) elevation; and (D) dune elevation for the area around Jupiter Inlet, FL. 
The rasterized model grids are a gridded representation of the suitability index from the model curves. The nesting area of interest in Figure 4 is centered around Jupiter Inlet and shows a higher suitability index for: slope (A); beach width (B); elevation (C); and dune peak (D) north of the inlet. The area north of the inlet has a steeper sloped beach, higher bare earth elevation, medium width beach, and a corresponding dune field. The area south of the inlet has less gradient variation from the shoreline to the dune line and results in the lower values represented in the rasterized grid from the model curves.

A weighted overlay approach was determined to be the best fit for the dataset and analysis goals. Overlay tools are commonly used in habitat models $[26,27]$. The model grids were reclassified to integer grids since the weighted overlay tool requires integerized grids instead of floating point. This changed the scale of the grids from 0 to 10 though still consistent with the trend of the model curve values. In order to choose appropriate parameter weights, an optimization process was conducted comparing actual site nest locations from Palm Beach County to suitability values in the model grids using 57 different parameter weighting schemes. Palm Beach County was selected as the model evaluation area since detailed nesting data were available for the 2008-2009 time period, which aligns with the timeframe of the lidar dataset. The 2008 nest site data were included to increase the sample size since there are approximately 7500 nests in the 2008 dataset compared with 5000 nest sites in the 2009 dataset and as stated previously the period between the 2008 nesting season and the collection of the 2009 lidar dataset was a time of tropical quiescence and therefore the coastal morphology is arguably similar for both nesting seasons.

\subsubsection{Model Development and Selection}

Utilizing costume scripting routines, 57 alternate weightings were evaluated by comparing sensitivity (true positive rate), detection rate, and detection prevalence to explore associations between actual C. caretta nesting sites and the overall habitat suitability values within each of the 57 models generated (Appendix B). To isolate the effect of a single parameter, four additional scenarios were also included using one parameter weighted at 100 percent. The presence of $C$. caretta nests identified in 2008 and 2009 was recorded for each corresponding cell and combined with null values where nests were not present at individual cells to create a grid for the spatial domain. Next, sensitivity, detection rate, and detection prevalence of each of the models tested were determined. This method provided a quantitative method for optimizing the weighting scheme developed, and allowed us to further evaluate whether the model could determine a relationship between model-generated habitat values and field-collected nest distributions. Methods followed Agresti [39] and Simonoff [40], statistical analyses used $\alpha=0.10$, and all analyses were conducted in R 3.2.3.

\subsubsection{Model Sensitivity Analysis}

A sensitivity analysis was performed in order to determine how robust the models were to the parameters and weightings included in the model. For each of the 57 weightings, a parameter was systematically removed from the model (e.g., elevation, slope, dune peak, or beach width) in order to determine how the predicted model index values responded to the exclusion of specific model parameters. The sensitivity analysis evaluates how well the area occupied by nests is predicted by reduced models. This method quantifies the importance of each parameter to overall model performance and allows for a more rigorous evaluation of index-based model outputs [41,42]. Once model sensitivity was quantified, the model weightings that optimized predictions for nesting occupancy were determined.

\section{Results}

\subsection{Model Selection}

The motivation for model development based on morphological parameters was to identify the terrestrial component of nesting habitat using lidar-derived data. After determining which 
morphological parameters were relevant to nest site selection, and exploring the relationships between each parameter and nesting data, various weighting schemes were explored to identify which parameters were most important for identifying habitat with high nesting suitability. Categorical data analysis $[39,40]$ was used to select the model(s) that best predicted C. caretta nest occurrence. As the available nesting density data obtained from nesting surveys did not contain any information or verification of non-nesting sites, the focus was on metrics that emphasized true positive values within the data set. Five models were selected that were best able to classify true positive values, made up of nest presence and presence of habitat with high suitability.

The metrics include sensitivity, detection rate, and detection prevalence as defined in confusion matrix. Sensitivity refers to the true positive rate, or the proportion of positive nesting occurrences that were properly identified. Detection rate and detection prevalence refer, respectively, to the proportion of true positive nesting occurrences and positive predicted nesting occurrences within the entire dataset. Of the 57 weighting scenarios (Figure 5), the models with the highest sensitivity and detection were driven by larger weights for elevation. Four out of five of these models had an elevation weight of 0.75 and all models had an elevation weight of at least 0.5 (Table 2). In comparison to the balanced model, in which each parameter was weighted equally, metrics increased in the top models, indicating that these models were better suited for identifying nesting habitat.

Table 2. Model sensitivity, detection rate, and detection prevalence of top five models as determined through comparative analysis of contingency tables from 57 candidate models. Results from equal-weight (balanced design) and one-parameter models are also listed.

\begin{tabular}{cccccccc}
\hline Model & \multicolumn{9}{c}{ Weighting Structure } & & Sensitivity & Detection Rate & Detection Prevalence \\
\hline & Slope & Beach Width & Elevation & Dune Peak & & & \\
\hline 17 & 0.13 & 0.06 & 0.75 & 0.06 & 0.830 & 0.725 & 0.828 \\
8 & 0.08 & 0.08 & 0.76 & 0.08 & 0.830 & 0.724 & 0.831 \\
2 & 0.06 & 0.06 & 0.75 & 0.13 & 0.802 & 0.700 & 0.807 \\
4 & 0.06 & 0.13 & 0.75 & 0.06 & 0.795 & 0.695 & 0.795 \\
35 & 0.25 & 0.08 & 0.5 & 0.17 & 0.748 & 0.653 & 0.742 \\
Balanced (40) & 0.25 & 0.25 & 0.25 & 0.25 & 0.663 & 0.579 & 0.644 \\
Elevation (60) & 0 & 0 & 1 & 0 & 0.891 & 0.778 & 0.638 \\
Slope (58) & 1 & 0 & 0 & 0 & 0.731 & 0.282 & 0.706 \\
Dune Peak (61) & 0 & 0 & 0 & 1 & 0.323 & 0.347 \\
Beach Width (59) & 0 & 1 & 0 & 0 & 0.265 & 0.231 & 0.239 \\
\hline
\end{tabular}

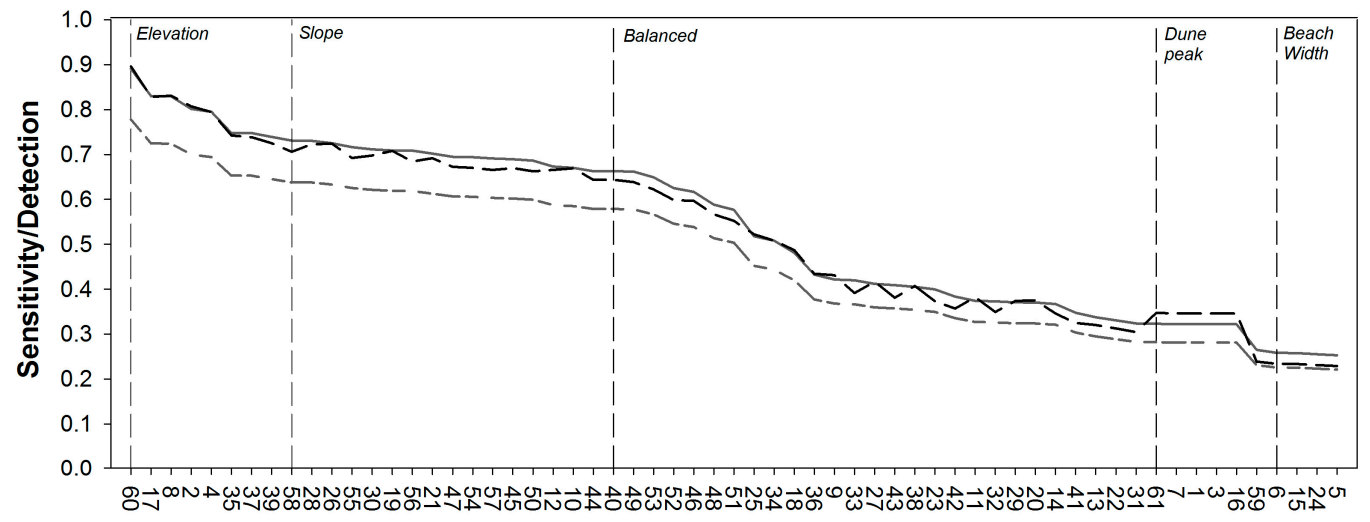

Model Number

Figure 5. Sensitivity (solid gray line), detection prevalence (dashed black line), and detection rate (gray dashed line) for predicting the occurrence of C. caretta nests for each of the 61 models tested. The weighting scheme for each model is listed in Appendix B.

Assessment of isolated individual parameter effects on model performance were consistent with weighting structures in the top five models in that the elevation model provided the highest sensitivities and detection metrics (Table 2). Following elevation, sensitivity decreased sequentially 
when slope, dune peak and beach width were individually used to identify nesting habitat suitability (Table 2). The results also indicated that while beach width may be the least useful parameter for accurately identifying high nesting habitat suitability (as determined by nest presence), it may be useful in identifying low suitable nesting habitat.

\subsection{Model Sensitivity Analysis}

The model was most sensitive to elevation - when elevation was removed from the model, each of the metrics decreased (Table 3). Slope was influential, but the model was not as sensitive to its exclusion if elevation was present. This indicates that slope is also an important parameter for predicting true nest habitat, especially in the absence of elevation information. When the slope, dune peak or beach width parameters were removed from the weighting schemes, the top resulting models were dominated by large weight values $(>0.5)$ for elevation, or the equal balanced model (Table 3 ).

Table 3. Top resulting models from model sensitivity analysis in which one parameter was removed from all 57 weighting schemes.

\begin{tabular}{|c|c|c|c|c|c|c|c|c|}
\hline \multirow{2}{*}{ Model } & & \multicolumn{4}{|c|}{ Weighting Structure } & \multirow{2}{*}{ Sensitivity } & \multirow{2}{*}{ Detection Rate } & \multirow{2}{*}{ Detection Prevalence } \\
\hline & & Slope & Beach Width & Elevation & Dune Peak & & & \\
\hline \multirow{5}{*}{$\begin{array}{c}\text { No } \\
\text { Elevation }\end{array}$} & 45 & 0.5 & 0.08 & 0 & 0.17 & 0.8777 & 0.7178 & 0.867 \\
\hline & 40 & 0.25 & 0.25 & 0 & 0.25 & 0.8723 & 0.7416 & 0.864 \\
\hline & 47 & 0.5 & 0.13 & 0 & 0.12 & 0.8589 & 0.7500 & 0.843 \\
\hline & 50 & 0.5 & 0.13 & 0 & 0.25 & 0.8492 & 0.6932 & 0.831 \\
\hline & 44 & 0.5 & 0.17 & 0 & 0.08 & 0.8349 & 0.7092 & 0.824 \\
\hline \multirow{5}{*}{ No Slope } & 35 & 0 & 0.08 & 0.5 & 0.17 & 0.932 & 0.814 & 0.937 \\
\hline & 40 & 0 & 0.25 & 0.25 & 0.25 & 0.930 & 0.812 & 0.934 \\
\hline & 37 & 0 & 0.13 & 0.5 & 0.12 & 0.921 & 0.804 & 0.925 \\
\hline & 26 & 0 & 0.08 & 0.5 & 0.25 & 0.915 & 0.799 & 0.919 \\
\hline & 39 & 0 & 0.17 & 0.5 & 0.08 & 0.909 & 0.794 & 0.912 \\
\hline \multirow{5}{*}{$\begin{array}{l}\text { No Dune } \\
\text { Peak }\end{array}$} & 40 & 0.25 & 0.25 & 0.25 & 0 & 0.934 & 0.816 & 0.936 \\
\hline & 26 & 0.17 & 0.08 & 0.5 & 0 & 0.934 & 0.816 & 0.931 \\
\hline & 19 & 0.13 & 0.12 & 0.5 & 0 & 0.926 & 0.808 & 0.928 \\
\hline & 35 & 0.25 & 0.08 & 0.5 & 0 & 0.918 & 0.801 & 0.920 \\
\hline & 10 & 0.08 & 0.17 & 0.5 & 0 & 0.908 & 0.793 & 0.911 \\
\hline \multirow{5}{*}{$\begin{array}{l}\text { No Beach } \\
\text { Width }\end{array}$} & 40 & 0.25 & 0 & 0.25 & 0.25 & 0.957 & 0.835 & 0.958 \\
\hline & 21 & 0.13 & 0 & 0.5 & 0.12 & 0.940 & 0.821 & 0.944 \\
\hline & 30 & 0.17 & 0 & 0.5 & 0.08 & 0.939 & 0.820 & 0.942 \\
\hline & 12 & 0.08 & 0 & 0.5 & 0.17 & 0.938 & 0.819 & 0.941 \\
\hline & 10 & 0.08 & 0 & 0.5 & 0.25 & 0.921 & 0.804 & 0.926 \\
\hline
\end{tabular}

Model 17 was determined to have the best weighting scheme for the study area. This model weights elevation the highest with a value of 0.75 and the remaining parameters have a value of 0.13 for slope and 0.06 for both beach width and dune peak. Results for Model 17 applied to the full study area are shown in Figure 6. The area is divided into five sections to better visualize the distribution of the $C$. caretta nesting suitability. The occurrences of each nesting suitability class were grouped together for the various sections. The sections were primarily divided at the county line, except for Palm Beach County which was divided into two sections. This was done to show the distribution in the area used for model evaluation (Figure 1; Figure 6B). Similarly, the breakout of the nesting suitability values for the sections reported as a percent of the total occurrence per section in Table 4 show that a majority of the area for each of the sections has a nesting suitability between 3 and 5 . It is important to remember that the weighting is applied to the entire study area, both cross-shore and alongshore which results in a spatial interpretation of the nesting suitability where each individual grid cell is assigned a nesting suitability value. Based on existing literature, it is known that $C$. caretta have preferred nesting habitat conditions and therefore some areas along the beach will not have high suitability or nesting.

Per area, the highest nesting suitability is modeled as occurring in Martin and Palm Beach Counties. This area of the coast has geomorphic features that align with the higher suitability in the model curves (Figure 3). While we know that nests occur in Broward and Dade counties, the results of the nesting suitability are a function of the morphological conditions that are shown to be less suitable than in the northern counties. 
Table 4. Nesting suitability for each section.

\begin{tabular}{cccccc}
\hline Suitability & Martin County & $\begin{array}{c}\text { Palm Beach } \\
\text { County North }\end{array}$ & $\begin{array}{c}\text { Palm Beach } \\
\text { County South }\end{array}$ & $\begin{array}{c}\text { Broward } \\
\text { County }\end{array}$ & Dade County \\
\hline 1 & $0.1 \%$ & $1 \%$ & $1 \%$ & $2 \%$ & $1 \%$ \\
2 & $11 \%$ & $15 \%$ & $16 \%$ & $10 \%$ & $7 \%$ \\
3 & $13 \%$ & $23 \%$ & $22 \%$ & $37 \%$ & $38 \%$ \\
4 & $25 \%$ & $24 \%$ & $32 \%$ & $27 \%$ & $20 \%$ \\
5 & $28 \%$ & $19 \%$ & $19 \%$ & $2 \%$ & $2 \%$ \\
6 & $11 \%$ & $7 \%$ & $6 \%$ & $1 \%$ & $0.4 \%$ \\
7 & $0.1 \%$ & $0.5 \%$ & $2 \%$ & $1 \%$ & $3 \%$ \\
8 & $7 \%$ & $5 \%$ & $2 \%$ & $0.03 \%$ & $0.03 \%$ \\
\hline
\end{tabular}

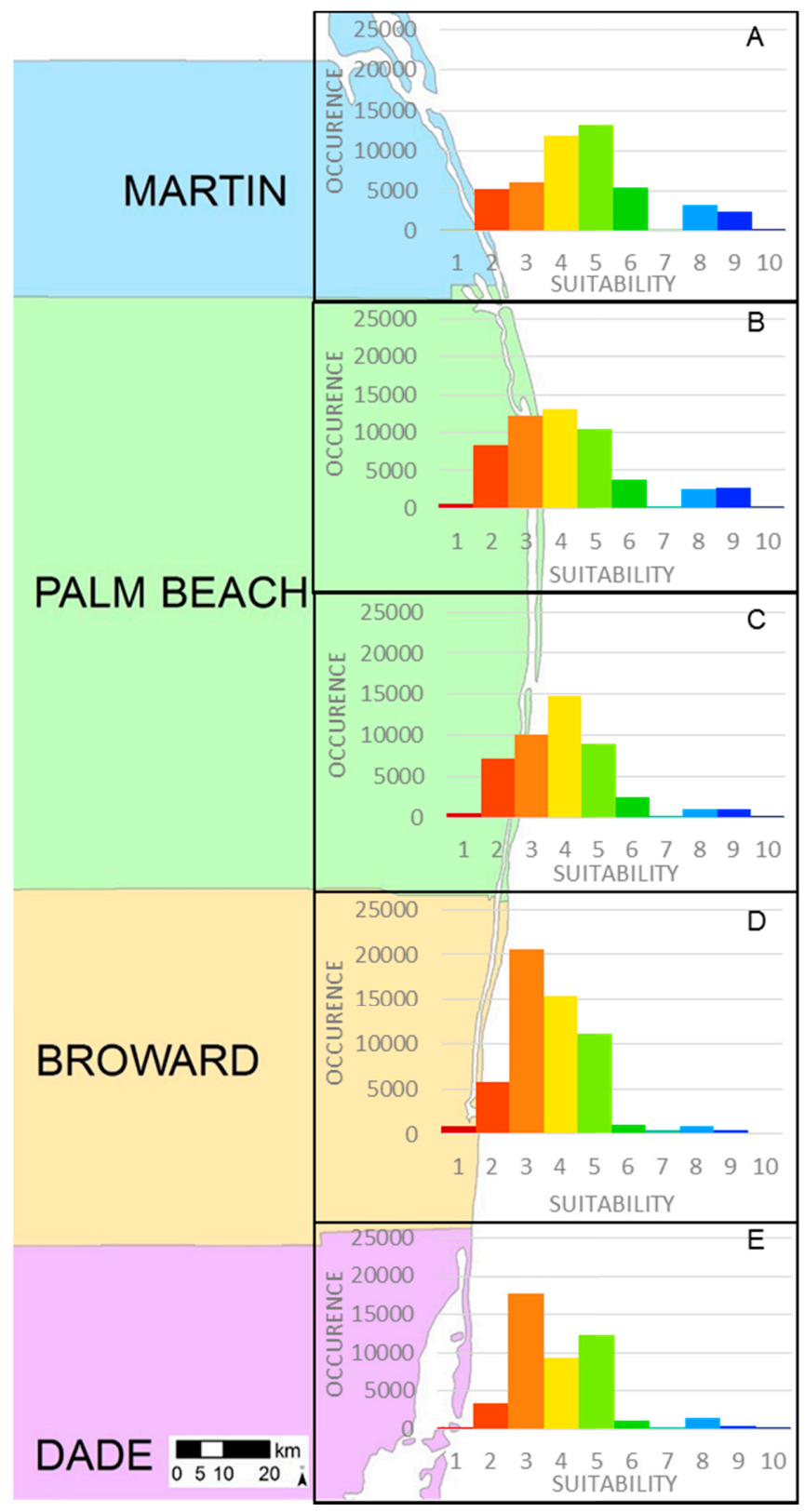

Figure 6. Nesting suitability distribution for the study area divided into sections for: (A) Martin County; (B) northern portion of Palm Beach County (area used in the model evaluation); (C) southern portion of Palm Beach County; (D) Broward County; and (E) a Dade County. 


\section{Discussion}

The results from our multi-model integrated approach for projecting $C$. caretta nesting site suitability can provide natural resource managers with a tool to determine if potential projects will impact sea turtle nests. Given that sea turtles are at their most vulnerable to predation during the egg and hatchling stage, developing a mechanism to gain a priori knowledge is critical because it reduces anthropogenic mortality vectors [2].

The use of remote sensing data is uniquely positioned to address the need for more efficient methods of assessing nesting habitat suitability on a regional scale. One interesting result from the study is the high influence that elevation had on the sensitivity of the model for this study area. The importance of elevation lends more power to utilizing remote sensing data for nesting habitat suitability assessment since acquiring elevation data on a regional scale is better suited for remote sensing techniques. Additionally, the use of remote sensing data provide the regional focus for determining nesting site suitability by addressing the need for a flexible model that allows for the variability in regional values to be included as input. This allows for a flexible model that can incorporate regional value ranges for the various morphological parameters [25-27].

The coastal environment is highly dynamic and thus having frequent surveys is essential to characterize the morphology. This is of particular importance in areas that experience substantial change during the nesting season such as from extreme storm events and/or anthropogenic changes. The 2008 and 2009 nesting season was a period of tropical quiescence with no extreme storm events impacting the area. Additionally, hindcast wave histories from Wave Information Study (WIS) Station 63460 for the 2008-2009 timeframe are plotted in Figure 7, which shows the average significant wave height is $1-\mathrm{m}$ with a mean wave direction of 107-degrees [43]. The station is located at the $347-\mathrm{m}$ depth contour at approximately 12-km offshore of Palm Beach County in the Atlantic Ocean. Since less than two percent of the waves are greater than or equal to $3-\mathrm{m}$, the low wave climate for this time period is assumed to cause limited morphological change. As such, the use of a single survey (2009 lidar dataset) for the model may not capture the subtle changes to the beach area that occurred during the 2008-2009 nesting season, but the over-arching morphology is expected to be fairly consistent between these two years.

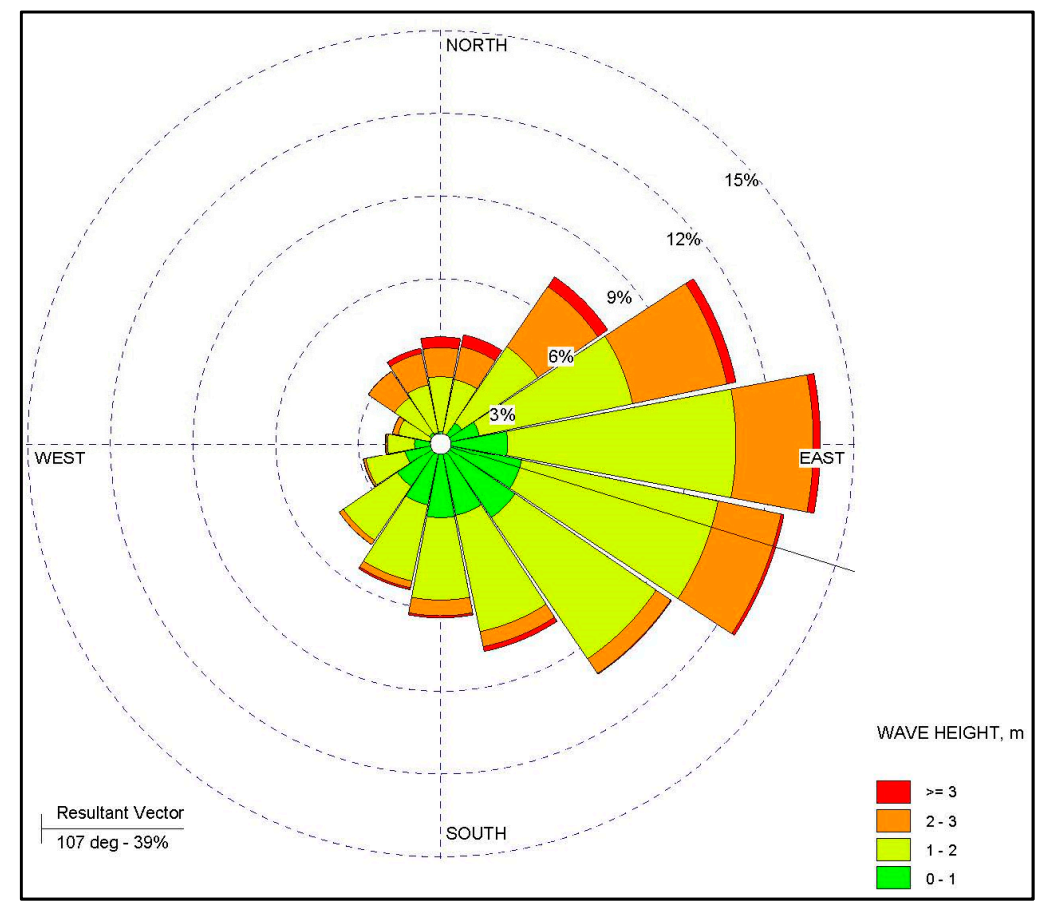

Figure 7. Wave rose for Station 63460 off the coast of Palm Beach County. 
While the nearshore features may influence nest site selection of $C$. caretta prior to emergence from the water [2], a study by Yamamoto et al. [4] indicated that the onshore characteristics are more influential than the nearshore features for determining nest density. Additionally, limiting the present study to subaerial morphological features ensures that the model approach will be applicable in areas where the collection of bathymetric lidar data is limited due to turbid environments.

Effective species management and conservation requires an understanding of how and why species are distributed spatially across a landscape with spatial datasets often biased towards where species are present, and not where they are absent [44]. This issue is magnified for rare or endangered species, where research is often focused on gathering basic information on the species, which can result in a larger bias towards presence-only data $[45,46]$. Barring the availability of true absence data to validate the model, the model was developed independently of the nesting data source, and the presence of nests were indicative of how well our model could predict nesting sites. While the model was optimized using detailed nesting data, high fidelity nesting data with coordinates is often difficult to obtain, does not exist in many locations, or is not released to protect nesting sites; however, the approach is intended to be flexible and adapt to the level of data that is available. For this study area, the equal weighting/balanced scenario had sensitivity and detection values of approximately 0.6 meaning that at a minimum, this model can be used with reasonable certainty for determining nesting habitat suitability with limited optimization. These results are an improvement from the field based approach described by Santos et al. [13] for collecting environmental data for a region to determine nesting suitability where the authors compared three habitat model approaches with an overall prediction rate of 40 percent [13].

As stated previously, dune vegetation and artificial lighting data were developed and set aside for qualitative comparison. These environmental and anthropogenic parameters may be important to consider for influencing nesting activity [4,12]. In addition, they may aid in evaluating habitat characteristics or quality, impacting site preference and mortality rates. Figure 8 shows the same section as Figure 4, highlighting approximated dune vegetation and the potential for artificial light pollution. Although it was outside the scope of this study to validate these parameters with ground truth data, they represent a preliminary way in which to investigate remotely sensed data for nesting habitat conditions. It should be noted that a more thorough inclusion of in-situ vegetation data as well as factoring lighting ordinances during nesting season would be required for site-specific assessment. Our modeling approach is easily adapted to include more data sources, and including such data not only highlights the potential role for new remotely sensed data products relating to nesting activities, but also, a starting point for how to incorporate them and begin to evaluate habitat characteristics. Thus, qualitative data comparisons can help explore links between habitat characteristics and nesting suitability. For example, lack of dune vegetation or potential for light pollution in areas that are highly suitable for nesting may help identify opportunities for habitat enhancement and improvement with maximum benefit to the species. This is seen in Figure 8, in which some areas south of Jupiter inlet have high suitability for nesting, but lack dune vegetation and have the potential for artificial lighting. This may be important to managers looking to prioritize and maximize strategies pertaining to nesting activity, including the maintenance of existing dune vegetation in dense nesting areas, identification of locations for dune vegetation enhancement in areas where it may be maximally beneficial, and reducing the potential for light pollution in nesting areas where possible. Thus, environmental and anthropogenic data in turtle nesting models such as this can be used as an initial screening tool, and when integrated with ancillary or site-specific data, can be used to help further identify and refine management strategies as they relate to turtle nesting habitat. 


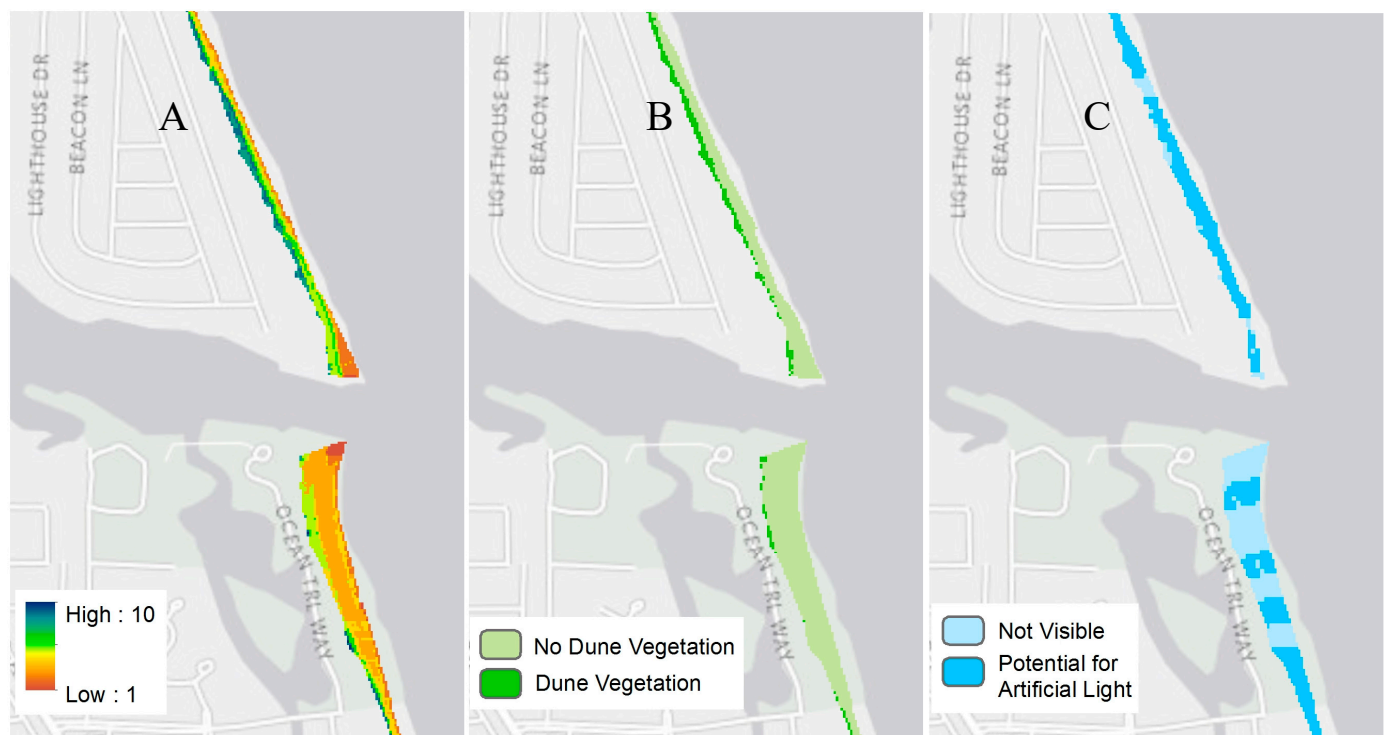

Figure 8. Nesting suitability, Model 17 (A); approximate dune vegetation (B); and potential artificial light pollution (C).

\section{Conclusions}

The methods developed in this study will be beneficial for monitoring the changing status of the coast as it relates to nesting habitat suitability for $C$. caretta as a result of anthropogenic factors and hydrodynamic conditions. In addition, the approach can be used to assess planned scenarios during the design phase and may lend insight for ways to improve the beach area and enhance nesting habitat suitability through beneficially managing sediment and other resources.

Future work should include additional analyses of the model approach to explore the influence of the morphological parameters in other locations. In addition, improved spatial integration of environmental and anthropogenic parameters could be helpful in determining their influence in nesting suitability as well as for conducting specific prioritization analyses for identifying management hotspots and areas of concern.

Acknowledgments: We thank K. Brutsche, M. Kjelland, and the anonymous reviewers for providing thoughtful, constructive comments.

Author Contributions: All authors have made major and unique contributions to the research and paper. Lauren Dunkin focused on the morphological spatial parameters and developed the suitability curves of these parameters that were used as input for the model. Molly Reif developed the environmental and anthropogenic spatial parameters and assisted with the model. Safra Altman and Todd Swannack were instrumental in the model evaluation.

Conflicts of Interest: The authors declare no conflict of interest.

\section{Appendix A}

Equations used to generate suitability indices are provided for the 200-km study area in southeast Florida, including Martin, Palm Beach, Broward, and part of Dade Counties. Breakpoints in the curves correspond to transition points that were determined from: (1) the regression curves, which provided site specific results for the probability of value ranges having low, medium, or high nesting suitability; (2) literature about preferred value ranges; and (3) input from subject matter experts on the preferred value ranges, and all contributed to the overall shape of each of the curves. The equations were determined as a step function using the suitability curve transition points to divide the curve into the various parts. Values between the steps or transition points were determined by fitting a line to the curve, which was either a linear interpolation or polynomial expansion. Refer to the main text 
for further information on the use of the regression curves, literature, and subject matter experts to identify transition points for curve development.

Values between the transition points for the slope were calculated as follows in Equations (A1)-(A4):

$$
\begin{gathered}
\text { slope } \leqslant 8 S I_{\text {slope }}=0.0062 \times\left(\text { slope }^{2}\right)+0.078 \times \text { slope } \\
8<\text { slope } \leqslant 11 S I_{\text {slope }}=1 \\
11<\text { slope } \leqslant 20 S I_{\text {slope }}=0.0058 \times\left(\text { slope }^{2}\right)-0.281 \times \text { slope }+3.40 \\
20<\text { slope } \leqslant 34 S_{\text {slope }}=-0.0071 \times \text { slope }+0.2429
\end{gathered}
$$

Values between the transition points for the beach width were calculated as follows in Equations (A5)-(A10):

$$
\begin{gathered}
\text { width } \leqslant 30 S I_{\text {width }}=-0.0004 \times\left(\text { width }^{2}\right)+0.0533 \times \text { width }-0.2374 \\
30<\text { width } \leqslant 40 S I_{\text {width }}=-0.02 \times(\text { width })+1.6 \\
40<\text { width } \leqslant 100 S I_{\text {width }}=-0.0082 \times(\text { width })+1.121 \\
100<\text { width } \leqslant 125 S I_{\text {width }}=-0.008 \times(\text { width })+1.1 \\
125<\text { width } \leqslant 175 S I_{\text {width }}=0.1 \\
175<\text { width } \leqslant 183 S I_{\text {width }}=-0.0125 \times(\text { width })+2.2875
\end{gathered}
$$

The bare earth elevation was calculated as follows for the normal distribution in Equation (A11):

$$
0<\text { elevation } \leqslant 10 S I_{\text {elevation }}=\frac{1}{\sqrt{ } 2 \pi} \times e^{-(\text {elevation })^{2}} / 2
$$

Values between the transition points for the dune elevation were calculated as follows in Equations (A12)-(A15):

$$
\begin{gathered}
\text { dune } \leqslant 4 S I_{\text {dune }}=0.0452 \times\left(\text { dune }^{2}\right)+0.0761 \times \text { dune } \\
4<\text { dune } \leqslant 7 S I_{\text {dune }}=-0.3 \times(\text { dune })+2.2 \\
7<\text { dune } \leqslant 10 S I_{\text {dune }}=0.1 \\
10<\text { dune } \leqslant 11 S I_{\text {dune }}=-0.1 \times(\text { dune })+1.1
\end{gathered}
$$

\section{Appendix B}

Table B1. Experimental design used to weight parameters for 57 model runs that utilized all four parameters. Four additional model runs, each using only one parameter, were also included in the analyses.

\begin{tabular}{ccccc}
\hline Weight Scenario & Slope & Beach Width & Elevation & Dune Peak \\
\hline $\mathbf{1}$ & 0.06 & 0.06 & 0.13 & 0.75 \\
$\mathbf{2}$ & 0.06 & 0.06 & 0.75 & 0.13 \\
$\mathbf{3}$ & 0.06 & 0.13 & 0.06 & 0.75 \\
$\mathbf{4}$ & 0.06 & 0.13 & 0.75 & 0.06 \\
$\mathbf{5}$ & 0.06 & 0.75 & 0.06 & 0.13 \\
\hline
\end{tabular}


Table B1. Cont.

\begin{tabular}{|c|c|c|c|c|}
\hline Weight Scenario & Slope & Beach Width & Elevation & Dune Peak \\
\hline 6 & 0.06 & 0.75 & 0.13 & 0.06 \\
\hline 7 & 0.08 & 0.08 & 0.08 & 0.76 \\
\hline 8 & 0.08 & 0.08 & 0.76 & 0.08 \\
\hline 9 & 0.08 & 0.17 & 0.25 & 0.5 \\
\hline 10 & 0.08 & 0.17 & 0.5 & 0.25 \\
\hline 11 & 0.08 & 0.25 & 0.17 & 0.5 \\
\hline 12 & 0.08 & 0.25 & 0.5 & 0.17 \\
\hline 13 & 0.08 & 0.5 & 0.17 & 0.25 \\
\hline 14 & 0.08 & 0.5 & 0.25 & 0.17 \\
\hline 15 & 0.08 & 0.76 & 0.08 & 0.08 \\
\hline 16 & 0.13 & 0.06 & 0.06 & 0.75 \\
\hline 17 & 0.13 & 0.06 & 0.75 & 0.06 \\
\hline 18 & 0.13 & 0.12 & 0.25 & 0.5 \\
\hline 19 & 0.13 & 0.12 & 0.5 & 0.25 \\
\hline 20 & 0.13 & 0.25 & 0.12 & 0.5 \\
\hline 21 & 0.13 & 0.25 & 0.5 & 0.12 \\
\hline 22 & 0.13 & 0.5 & 0.12 & 0.25 \\
\hline 23 & 0.13 & 0.5 & 0.25 & 0.12 \\
\hline 24 & 0.13 & 0.75 & 0.06 & 0.06 \\
\hline 25 & 0.17 & 0.08 & 0.25 & 0.5 \\
\hline 26 & 0.17 & 0.08 & 0.5 & 0.25 \\
\hline 27 & 0.17 & 0.17 & 0.16 & 0.5 \\
\hline 28 & 0.17 & 0.17 & 0.5 & 0.16 \\
\hline 29 & 0.17 & 0.25 & 0.08 & 0.5 \\
\hline 30 & 0.17 & 0.25 & 0.5 & 0.08 \\
\hline 31 & 0.17 & 0.5 & 0.08 & 0.25 \\
\hline 32 & 0.17 & 0.5 & 0.17 & 0.16 \\
\hline 33 & 0.17 & 0.5 & 0.25 & 0.08 \\
\hline 34 & 0.25 & 0.08 & 0.17 & 0.5 \\
\hline 35 & 0.25 & 0.08 & 0.5 & 0.17 \\
\hline 36 & 0.25 & 0.13 & 0.12 & 0.5 \\
\hline 37 & 0.25 & 0.13 & 0.5 & 0.12 \\
\hline 38 & 0.25 & 0.17 & 0.08 & 0.5 \\
\hline 39 & 0.25 & 0.17 & 0.5 & 0.08 \\
\hline 40 & 0.25 & 0.25 & 0.25 & 0.25 \\
\hline 41 & 0.25 & 0.5 & 0.08 & 0.17 \\
\hline 42 & 0.25 & 0.5 & 0.13 & 0.12 \\
\hline 43 & 0.25 & 0.5 & 0.17 & 0.08 \\
\hline 44 & 0.5 & 0.08 & 0.17 & 0.25 \\
\hline 45 & 0.5 & 0.08 & 0.25 & 0.17 \\
\hline 46 & 0.5 & 0.13 & 0.12 & 0.25 \\
\hline 47 & 0.5 & 0.13 & 0.25 & 0.12 \\
\hline 48 & 0.5 & 0.17 & 0.08 & 0.25 \\
\hline 49 & 0.5 & 0.17 & 0.17 & 0.16 \\
\hline 50 & 0.5 & 0.17 & 0.25 & 0.08 \\
\hline 51 & 0.5 & 0.25 & 0.08 & 0.17 \\
\hline 52 & 0.5 & 0.25 & 0.13 & 0.12 \\
\hline 53 & 0.5 & 0.25 & 0.17 & 0.08 \\
\hline 54 & 0.75 & 0.06 & 0.06 & 0.13 \\
\hline 55 & 0.75 & 0.06 & 0.13 & 0.06 \\
\hline 56 & 0.76 & 0.08 & 0.08 & 0.08 \\
\hline 57 & 0.75 & 0.13 & 0.06 & 0.06 \\
\hline 58 & 1.00 & 0.00 & 0.00 & 0.00 \\
\hline 59 & 0.00 & 1.00 & 0.00 & 0.00 \\
\hline 60 & 0.00 & 0.00 & 1.00 & 0.00 \\
\hline 61 & 0.00 & 0.00 & 0.00 & 0.00 \\
\hline
\end{tabular}




\section{References}

1. U.S. Fish and Wildlife Services (USFWS). Available online: http://www.fws.gov/northflorida/seaturtles / 2014_Loggerhead_CH/Terrestrial_critical_habitat_loggerhead.html (accessed on 3 March 2016).

2. Provancha, J.A.; Ehrhart, L.M. Sea Turtle Nesting Trends at John F. Kennedy Space Center and Cape Canaveral Air Force Station, Florida, and Relationships with Factors Influencing Nest Site Selection. In Ecology of East Florida Sea Turtles, Proceedings of the Cape Canaveral, Florida Sea Turtle Workshop, Cape Canaveral, FL, USA, 26-27 February 1987; National Oceanographic and Atmospheric Administration Technical Report NMFS-53; Miami Laboratory: Miami, FL, USA, 1987; pp. 33-44.

3. Long, T.M.; Angelo, J.; Weishampel, J.F. LiDAR-derived measures of hurricane- and restoration-generated beach morphodynamics in relation to sea turtle nesting behavior. Int. J. Remote Sens. 2011, 32, $231-241$. [CrossRef]

4. Yamamoto, K.H.; Powell, R.L.; Anderson, S.; Sutton, P.C. Using LiDAR to quantify topographic and bathymetric details for sea turtle nesting beaches in Florida. Remote Sens. Environ. 2012, 125, $125-133$. [CrossRef]

5. Dickerson, D.D.; Smith, J.; Wolters, M.; Theriot, C.; Reine, K.J.; Dolan, J. A review of beach nourishment impacts on marine turtles. Shore Beach 2007, 75, 49-56.

6. Wood, D.W.; Bjorndal, K.A. Relation of Temperature, Moisture, Salinity, and Slope to Nest Site Selection in Loggerhead Sea Turtles; COPEIA, No. 1; American Society of Ichthyologists and Herpetologists: Lawrence, KS, USA, 2000; pp. 119-128.

7. Brock, K.A.; Reece, J.S.; Ehrhart, L.M. The effects of artificial beach nourishment on marine turtles: Difference between loggerhead and green turtles. Restor. Ecol. 2009, 17, 297-307. [CrossRef]

8. Landry, A.M.; Hughes, C.L. Guide to Managing Sea Turtle Nesting Habitat on the Upper Texas Coast; Coastal Management Program; Texas General Land Office: Austin, TX, USA, 2008; p. 36.

9. Garmestani, A.S.; Percival, F.; Portier, K.M.; Rice, K.G. Nest-Site Selection by the Loggerhead Sea Turtle in Florida's Ten Thousand Islands. J. Herpetol. 2000, 34, 504-510. [CrossRef]

10. Hays, G.C.; Mackay, A.; Adams, C.R.; Mortimer, J.A.; Speakman, J.R.; Boerema, M. Nest Site Selection by Sea Turtles. J. Mar. Biol. 1995, 75, 667-674. [CrossRef]

11. Botha, M. Nest Site Fidelity and Nest Site Selection of Loggerhead, Caretta caretta, and Leatherback, Dermochelys coriacea, Turtles in KwaZulu-Natal, South Africa. Master's Thesis, Nelson Mandela Metropolitan University, Port Elizabeth, South Africa, 2010; p. 122.

12. Varela-Acevedo, E.; Eckert, K.L.; Eckert, S.A.; Cambers, G.; Horrocks, J.A. Sea Turtle Nesting Beach Characterization Manual. In Examining the Effects of Changing Coastline Processes on Hawksbill Sea Turtle (Eretmochelys imbricate) Nesting Habitat; Master's Project; Nicholas School for the Environmental and Earth Sciences, Duke University: Beaufort, NC, USA, 2009; pp. 46-97.

13. Santos, K.C.; Tague, C.; Alberts, A.C.; Franklin, J. Sea turtle nesting habitat on the US Naval Station, Guantanamo Bay, Cuba: A comparison of habitat suitability index models. Chelonian Conserv. Biol. 2006, 5, 175-187. [CrossRef]

14. Salmon, M. Artificial night lighting and sea turtles. Biologist 2003, 50, 163-168.

15. Yamamoto, K.H.; Anderson, S.J.; Sutton, P.C. Measuring the effects of morphological changes to sea turtle nesting beaches over time with LiDAR data. J. Sea Res. 2015, 104, 9-15. [CrossRef]

16. Kobayashi, D.R.; Polovina, J.J.; Parker, D.M.; Kamezaki, N.; Cheng, I.; Uchida, I.; Dutton, P.H.; Balazs, G.H. Pelagic habitat characterization of loggerhead sea turtles, Caretta caretta, in the North Pacific Ocean (1997-2006): Insights from satellite tag tracking and remotely sensed data. Exp. Mar. Biol. Ecol. 2008, 356, 96-114. [CrossRef]

17. Hawkes, L.A.; Broderick, A.C.; Coyne, M.S.; Godfrey, M.H.; Godley, B.J. Only some like it hot-Quantifying the environmental niche of the loggerhead sea turtle. Divers. Distrib. 2007, 13, 447-457. [CrossRef]

18. Kaplan, D.M.; Planes, S.; Fauvelot, C.; Brochier, T.; Lett, C.; Bodin, N.; Le Loc'h, F.; Tremblay, Y.; Georges, J. New tools for the spatial management of living marine resources. Curr. Opin. Environ. Sustain. 2010, 2, 88-93. [CrossRef]

19. Brooks, R.P. Improving habitat suitability index models. Wildl. Soc. Bull. 1997, 25, 163-167.

20. Roloff, G.J.; Kernohan, B.J. Evaluating reliability of habitat suitability index models. Wildl. Soc. Bull. 1999, 27, 973-985. 
21. Raxworthy, C.J.; Martinez-Meyer, E.; Horning, N.; Nussbaum, R.A.; Schneider, G.E.; Ortega-Huerta, M.A.; Townsend, P.A. Predicting distributions of known and unknown reptile species in Madagascar. Nature 2003, 426, 837-841. [CrossRef] [PubMed]

22. Goldberg, C.S.; Waits, L.P. Using habitat models to determine conservation priorities for pond-breeding amphibians in a privately-owned landscape of northern Idaho, USA. Biol. Conserv. 2009, 142, 1096-1104. [CrossRef]

23. Dalponte, M.; Bruzzone, L.; Gianelle, D. Tree species classification in the Southern Alps based on the fusion of very high geometrical resolution multispectral/hyperspectral images and LiDAR data. Remote Sens. Environ. 2012, 123, 258-270. [CrossRef]

24. Tattoni, C.; Rizzolli, F.; Pedrini, P. Can LiDAR data improve bird habitat suitability models? Ecol. Model. 2012, 245, 103-110. [CrossRef]

25. Curnutt, J.L.; Comiskey, J.; Nott, M.P.; Gross, L.J. Landscape-based spatially explicit species index models for Everglades restoration. Ecol. Appl. 2000, 10, 1849-1860. [CrossRef]

26. Store, R.; Kangas, J. Integrating spatial multi-criteria evaluation and expert knowledge for GIS-based habitat suitability modeling. Landsc. Urban Plan. 2001, 55, 79-93. [CrossRef]

27. Store, R.; Jokimaki, J. A GIS-based multi-scale approach to habitat suitability modeling. Ecol. Model. 2003, 169, 1-15. [CrossRef]

28. Fish and Wildlife Service. Endangered and threatened wildlife and plants; designation of critical habitat for the Northwest Atlantic Ocean distinct population segment of the loggerhead sea turtle: Final rule. Fed. Regist. 2014, 79, 39755-39854.

29. Shamblin, B.M.; Dodd, M.G.; Bagley, D.A.; Ehrhart, L.M.; Tucker, A.D.; Johnson, C.; Carthy, R.R.; Scarpino, R.A.; McMichael, E.; Addison, D.S.; et al. Genetic structure of the southeastern United States loggerhead turtle nesting aggregation: Evidence of additional structure within the peninsular Florida recovery unit. Mar. Biol. 2011, 158, 571-587. [CrossRef]

30. Schroeder, B.A.; Foley, A.M.; Bagley, D.A. Nesting patterns, reproductive migrations, and adult foraging areas of loggerhead turtles. In Loggerhead Sea Turtles; Bolten, A.B., Witherington, B.E., Eds.; Smithsonian Books: Washington, DC, USA, 2003; pp. 114-124.

31. Tucker, A.D. Nest site fidelity and clutch frequency of loggerhead turtles are better elucidated by satellite telemetry than by nocturnal tagging efforts: Implications for stock estimation. J. Exp. Mar. Biol. Ecol. 2010, 383, 48-55. [CrossRef]

32. Wozencraft, J.M.; Lillycrop, W.J. JALBTCX Coastal Mapping for the USACE. Int. Hydrogr. Rev. 2006, 7, $28-37$.

33. Dunkin, L.M.; Reif, M.K.; Swannack, T.M.; Gerhardt-Smith, J. Conceptual Model Development for Sea Turtle Nesting Habitat: Support for USACE Navigation Projects; No. ERDC TN-DOER R23; Army Corps of Engineers Vicksburg MS Engineer Research and Development Center: Vicksburg, MS, USA, 2015; pp. 1-8.

34. Dunkin, L.M. Monitoring Shore Protection Projects using 3D Spatial Data. In Proceedings of the Coastal Engineering Practices Conference, San Diego, CA, USA, 21-24 August 2011; p. 12.

35. Weber, K.M.; List, J.H.; Morgan, L.M. An Operational Mean High Water Datum for Determination of Shoreline Position for Topographic LiDAR Data; Open-File Report 2005-1027; U.S. Geological Survey: Woods Hole, MA, USA, 2005.

36. Environmental Systems Research Institute (ESRI). ArcGIS Desktop: Release 10.1; ESRI: Redlands, CA, USA, 2016.

37. Tucker, C.J. Red and photographic infrared linear combinations for monitoring vegetation. Remote Sens. Environ. 1979, 8, 127-150. [CrossRef]

38. Homer, C.G.; Dewitz, J.A.; Yang, L.; Jin, S.; Danielson, P.; Xian, G.; Coulston, J.; Herold, N.D.; Wickham, J.D.; Megown, K. Completion of the 2011 National Land Cover Database for the conterminous United States-Representing a decade of land cover change information. Photogramm. Eng. Remote Sens. 2015, 81, 345-354.

39. Agresti, A. Categorical Data Analysis, 3rd ed.; John Wiley and Sons, Inc.: New York, NY, USA, 2012.

40. Simonoff, J.S. Analyzing Categorical Data; Springer: New York, NY, USA, 2003.

41. Pollack, J.B.; Cleveland, A.; Palmer, T.A.; Reisinger, A.S.; Montagna, P.A. A restoration suitability index model for the eastern oyster (Crassostrea virginica) in the Mission-Aransas estuary, TX, USA. PLoS ONE 2012, 7, e40839. 
42. Swannack, T.M.; Reif, M.K.; Soniat, T.M. A robust, spatially-explicit model for identifying oyster restoration sites: Case studies on the Atlantic and Gulf Coasts. J. Shellfish Res. 2014, 33, 395-408. [CrossRef]

43. Wave Information Study (WIS). U.S. Army Corps of Engineers Wave Information Studies Project Documentation, 2010. Available online: http:/ / wis.usace.army.mil/wis_documentation.html (accessed on 14 June 2016).

44. Pearce, J.L.; Boyce, M.S. Modelling distribution and abundance with presence-only data. J. Appl. Ecol. 2006, 43, 405-412. [CrossRef]

45. Guisan, A.; Zimmermann, N.E. Predictive habitat distribution models in ecology. Ecol. Model. 2000, 135, 147-186. [CrossRef]

46. Hirzel, A.H.; Lay, G.L.; Helfer, V.; Randin, C.; Guisan, A. Evaluating the ability of habitat suitability models to predict species presences. Ecol. Model. 2006, 199, 142-152. [CrossRef]

(C) 2016 by the authors; licensee MDPI, Basel, Switzerland. This article is an open access article distributed under the terms and conditions of the Creative Commons Attribution (CC-BY) license (http://creativecommons.org/licenses/by/4.0/). 